\title{
The Role of Cupping Therapy (CT) In Pain Tackling, an Insight into Mechanism Therapeutic Effects and its Relevance in Current Medical Scenario
}

\author{
Mudassir Alam ${ }^{1}$, Kashif Abbas ${ }^{2}$ \\ ${ }^{1,2}$ Department of Zoology, Aligarh Muslim University, Aligarh- 202002 INDIA
}

\begin{abstract}
Cupping Therapy (CT) is popular as 'Al-Hijama' in Egypt and Arabic countries which is an ancient traditional method which is practiced for the treatment of various medical conditions, especially claims to be a potential remedy in pain related diseases. Basically, this therapy is an integrated part of the Complementary and alternative medicine, it has got utmost popularity in Unani system of medicine too. Although cupping therapy has been a treatment for long, but its mode of action is not well established yet, several studies have been conducted so far in order to investigate the actual mechanisms behind this therapy, still cupping therapy is a matter of dilemma in medical science. So far, several theories and hypothesis have been put forwarded to explain the effects produced by the cupping therapy. This article provides an overview of cupping therapy practice and associated adverse events, therapeutics potential and current prospective in today's medical science.
\end{abstract}

KEYWORDS: Alternative medicine, Cupping Therapy, Hijama, Inflammation, Pain, Traditional Practice.

\section{INTRODUCTION}

Pain is one of the most common factors for seeking therapeutic alternatives to conventional therapies more severe is the pain, more frequent is the use of such therapies [1]. Cupping Therapy is a physical treatment generally given by the unani practitioner or other therapists, which utilize a glass cup to create suction on the skin over a painful area or required point at the body [2]. The World Health Organization's (WHO) definition of cupping is a therapeutic method which includes the application of suction by creating a vacuum. That is typically done using fire in a cup or jar on the dermis of the affected point of the body. One of the oldest medical texts Eber's papyrus provides an illustration about cupping therapy. The ancient Greek physician Hippocrates extensively compiled the actual descriptions of the cupping (Hijamah) application. He has basically given description over two different types of cups: one with a narrow opening and a long handle while other with a wider opening. The first type, narrow opening cup was used to treat and chronic accumulation of fluids, while the second type was used in treating the spread of pain as in case of gout and arthritis [3]. Way back, long before several evidences had been uncovered to support the application of cupping therapy tools as a therapeutic procedure, humans used to rely on their ability to draw and suck the irritants through body surface. CT was very much prevalent historical treatment in Arabic and Islamic countries. This has been reported that it was acclaimed by Arabic and Islamic physicians such as Ibn Sina, Al-Zahrawi. Al-Zahrawi initially described the sites of cupping at body and illustrated cupping tools application as well. Hijamah $(\mathrm{CT})$ practice spread to Italy and subsequently, the rest of Europe between the $14^{\text {th }}$ and $17^{\text {th }}$ centuries during the Renaissance [4]. Basically, Cupping therapy is a simple and potential application of quick, vigorous, and ultimate strokes to stimulate muscles, particularly much useful in treatment of aches and extreme pains of limbs, neck, shoulders and back. It is practiced with round glass cups which are shaped like glass balls that have required opening at one end. This cupping therapy involves placing glass suction cups on painful body parts for vacuum creation which ultimately restore the flow. An experimental study strongly suggested that cupping is also helpful in regulating both innate and acquired immune responses [5]. Thereby it has been observed that cupping system carries the potential to enhance the quality of life due to which this practice is still followed.

\section{PROCEDURE OF CUPPING THERAPY}

Cupping therapy (Hijamah) is usually done by putting on small round glass cups at the site of pain in body. A proper sized cup is positioned on the particular area and therapist uses a method of suction to suck the air inside the cup. The cup is equipped with a rolled rim in order to ensure skintight contact so that negative pressure can be created at specific point of the body. The negative 


\section{International Journal of Current Science Research and Review}

ISSN: 2581-8341

Volume 04 Issue 07 July 2021

DOI: 10.47191/ijcsrr/V4-i7-16, Impact Factor: 5.825

IJCSRR@ 2021

www.ijcsrr.org

pressure is generated by pumping that creates vacuums. This pressure ultimately fixes the cup onto the skin surface and produces suction effect which results in pulling the skin upwards into the cup. It has been established that the suction cups are usually kept in place for 5 to 20 minutes [6]. The mouth of glass cup is placed in a way that it firmly attaches over the required location on the skin. Generally, the application sites are viz. back, chest, abdomen, buttock, and the areas of plentiful muscle. The treated area is cleaned carefully, disinfected, and dressing is done with utmost care. The dressing is usually kept for 48 hours following the session of this therapy [7]. Technique of cupping therapy might be responsible for certain alteration at the cellular, tissues and organs level. Some Specific interventions may suppress or enhance body hormones, also it might stimulate or modulate immunity.

\section{MODE OF ACTION}

The actual mechanism of cupping therapy needs to be elucidated in a scientific way, there have been so many questions striking from time to time regarding the exact role of cupping in treating various diseases and medical conditions that seem resistant to existing treatment modalities. This has been reported that cupping therapy works via creating specific alterations in local tissue structures those results in local negative pressure in the cups which stretches the nerve and muscle ultimately causing an immense increase in blood circulation and leading to auto-hemolysis [8]. Through various studies it may be accepted that local negative pressure may affect tissue structure and increase blood circulation but this is actually not enough to explain benefits of cupping therapy in treatment of some medical conditions such as cellulitis, migraine, headache and hypertension The exact mechanism of action of cupping therapy is not well established yet, there have been multiple theories proposed so far. Here in this review article, we are discussing some of the possible theories that seem to be playing a crucial role and describe the effects of cupping therapy.

\subsection{Pain Modulation theory}

This pain modulation theory is also known as the Diffuse Noxious Inhibitory Controls (DNICs). Which is based on the hypothesis that "pain inhibits pain" or one type of pain facades another type of pain. The pathway is activated when two concomitant painful stimuli are applied at the same time [9]. It has been demonstrated successfully in experimental animal studies that activation of the pain pathway actually triggered by a distant noxious stimulus which ultimately causes inhibition of the primary pain. This pain modulation theory claims that the local vibration or scratching done during cupping therapy causes a stimulus which triggers the activation of DNICs that finally lead to the relief of primary pain.

\subsection{Reflex zone theory}

There is always a strong coordination between different organs of the body. This coordination is mediated by the interactions between nerves, chemicals, and muscles. Thus, any chaos in one or more than one organ causes external manifestations which can be detected at a site distal to the disturbed organ [10]. The external manifestations are dependent on the intensity of various factors. Some studies on animal showed that the somatic stimulation of skin or the peripheral joints can lead to the significant effects on the organ system such as cardiovascular, urinary, and gastrointestinal system functioning . Reflexes may be either inhibitory or excitatory in relation of organ function. Their main action is attained through spinal pathways, supra-spinal and cortical canter's [11]. The organ functioning is greatly affected due to a reduction in the circulating blood and tissue fluids. Therefore, the theory of reflex zone hypothesized that the application of the cupping therapy cups over the skin causes stimulation of the skin receptors actively that eventually results in the improved blood circulation through the neural connections to the affected organ.

\subsection{Pain-gate theory}

According to the theory of pain gate, cupping therapy seem to reduce pain intensity by influencing the communication routes of pain transmission right from a stimulated area to the brain and backward [12]. It has been reported that the pain signals are actually carried by the both small diameter (A-delta and C) and the large-diameter (A-beta) nociceptive nerve fibber's to the synapse into a transmission cell up to the dorsal horn of spinal cord in this area pain modulation takes place through a network of interneurons and presynaptic small pain gates[13]. Cupping therapy may relieve pain through anti-nociceptive and anti-irritative effects. However, it is still unknown to what extent cupping induces such mechanisms. Cupping is thought to stimulate pain receptors, which increases the frequency of impulses ultimately leading to the closure of pain gates and thus pain reduced. this area of study still needs to be explored. 


\section{International Journal of Current Science Research and Review}

ISSN: 2581-8341

Volume 04 Issue 07 July 2021

DOI: 10.47191/ijcsrr/V4-i7-16, Impact Factor: 5.825

IJCSRR@ 2021

www.ijcsrr.org

\subsection{Blood detoxification theory}

This theory explains how the underlying mechanism of cupping therapy relieves the body of toxins and harmful materials. it removes toxic substances from the affected area where the cups are used. According to the blood detoxification theory, there is a little bit decrease in uric acid, HDL, LDL, and various other hematological enzymes. Several studies have found significant differences in a variety of biochemical, immunological and hematological parameters between venous and cupping blood [14]. Several studies have found significant differences in a variety of biochemical, hematological and immunological parameters between venous and cupping blood. The flow of blood in cupping tends to break up obstructions and create an avenue for toxins to be drawn out of the body. Several cups can be placed on a patient's body at once. Cupping may aid in the excretion of old red blood cells [15]. Increased blood flow may promote the release of toxins and wastes, improve local nutrition, ultimately boost the metabolism, supporting the healthy aspect and eliminating pathogenic factors [16]. In a study it was seen that the heavy metals such as mercury, silver and lead can also be removed from blood through cupping therapy [17]. therefor, this therapy may also useful in treating diseases associated with heavy metal deposition and contamination in different parts of the body.

\section{CLASSIFICATION OF CUPPING THERAPY}

Cupping was previously divided into dry and wet cupping, but in $2016 \mathrm{Al}$-Bedah et al. introduced a new classification that included various categories such as technical types, suction power, suction method, materials inside cups, area treated, and other cupping types [18]. Several other modifications have also been introduced in cupping therapy.

\subsection{Dry Cupping}

Dry cupping can also be referred to as static cupping or retained cupping. Typically, the cups are left on the skin for up to 15 minutes [18]. It has been observed that the Negative pressure is generated inside the cups during dry cupping via various suction methods such as fire, manual pump, or electrical suction. When using a manual pump, the number of suctions potentially controls the pressure inside the cup, As the number rises, the negative pressure inside the cup increase [19]. Some findings suggest that this negative pressure leads to the much protrusion of the skin. Henceforth cupping therapy has not gain attention in medical science.

\subsection{Wet Cupping}

Wet cupping is also called full cupping, bleeding cupping and bloodletting cupping. Wet cupping is a part of traditional medicine and most commonly used in pain related problems [20]. Generally, it involves scraping of that areas skin by a surgical instrument before applying the cups to suck the blood. There have been various adverse episodes reported in wet cupping therapy. The main disadvantages of this method include an increased risk of infection, vasovagal attacks, and scar formation [18]. There are many research articles describing the severe consequences of wet cupping therapy, thus this wet cupping has not given much importance in medical science.

\subsection{Flash cupping}

Flash cupping is basically known as empty cupping. In order to stimulate the targeted area, the cup is applied for a brief period of less than 30 seconds. It entails applying quick suction of medium to light pressure to the targeted area [20]. In case where dry cupping is not recommended, this flash cupping method can be used as it is thought to be more favorable. For instance, in young people and women. It is possible to make it with just one cup or four medium-sized cups.

\subsection{Massage cupping}

Moving cupping, gliding cupping and dynamic cupping are all attributed for massage cupping. Olive oil, peppermint oil, and lavender oil are just a few of the oils that are commonly used in massage cupping therapy. [21]. Massage therapy is done by applying oil over the skin and moving the cups at the treated area using weak suction. Basically, this type of cupping is generally recommended for both young and elderly people. 


\section{International Journal of Current Science Research and Review}

ISSN: 2581-8341

Volume 04 Issue 07 July 2021

DOI: 10.47191/ijcsrr/V4-i7-16, Impact Factor: 5.825

IJCSRR@ 2021

www.ijjcsrr.org

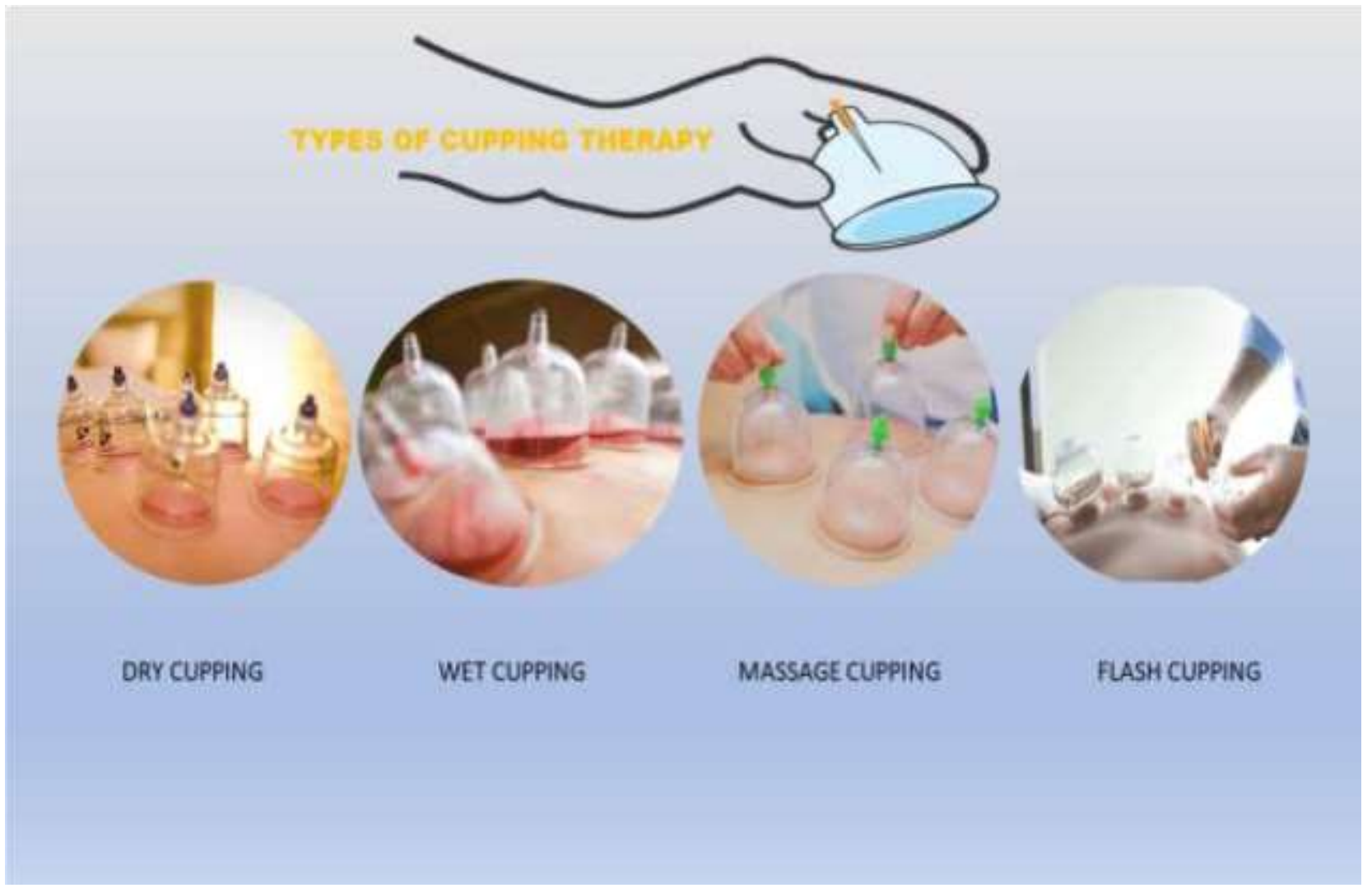

Figure 1: Types of Cupping therapy

\section{SUCTION POWER IN CUPPING THERAPY}

The negative pressure level created inside the cups is used to classify this type of cupping. The pressure levels can be classified as light, medium, strong, and pulsatile. Suction power is actually the pressure applied over the targeted area by the practitioner in order to ooze out.

\subsection{Light cupping pressure}

Light cupping pressure is primarily used in children, elderly and sensitive body parts viz. face. It can be combined with massage, dry cupping, and flash cupping techniques. Using one to two full manual suction pumps, the therapist creates weak suctions in the cup. A pressure level between 100 and less than 300 millibar is considered light cupping pressure (mb) [22]. Its main advantage is that it leaves no cupping marks on the majority of patients. The cup, however, tends to fall during the therapy session due to the light pressure.

\subsection{Medium cupping pressure}

Unlike light cupping pressure, medium cupping is associated with leaving dense marks on the body parts therefore, it is not recommended to apply over sensitive body areas such as face and forehead. The pressure level employed is between 300 and 500 $\mathrm{mb}$. Generally, it is created by putting 3-4 full manual suction pumps. This type of pressure cupping is used for common purposes $[22,18]$. Although pressure may be altered in between 300-500 mb depending upon the situation.

\subsection{Strong cupping pressure}

Strong cupping pressure entails using a pressure level more than $500 \mathrm{mb}$. usually done with the help of 5 or more full manual suction pumps. This cupping pressure is not at all appropriate for children or the elder patients. It has strong potential to cause inflammation, skin burns, dermatitis and severe pain [18]. Strong cupping pressure is rarely applied due to its severity of skin burns and pain. There have been so many cases reported where strong cupping pressure has imposed serious side effects and left permanent marks on the body. 


\section{International Journal of Current Science Research and Review}

ISSN: 2581-8341

Volume 04 Issue 07 July 2021

DOI: 10.47191/ijcsrr/V4-i7-16, Impact Factor: 5.825

IJCSRR@ 2021

www.ijcsrr.org

\subsection{Pulsatile cupping pressure}

In case of pulsatile cupping pressure differential pulses of pressure are used which are generated with the help of mechanical device. Every 2 seconds, one pulse is generated. The actual generated pressure level lies between 100 and $200 \mathrm{mb}$. Its application has been limited to symptomatic pain relief in patients suffering from knee osteoarthritis [23]. Flexible silicone and plastic cups are frequently used in this type cupping by practitioner.

\section{ADDED CUPPING THERAPY TYPES}

This classification of cupping is based on the several additional materials that are potentially used in conjunction with the therapy cups. It consists of the following types viz.

\subsection{Moxa cupping or Hot cupping}

Moxa cupping is basically the combined integrative form of cupping which is a combination of heat and a herb popularly known as Moxa. The Moxa is made up of dried Mugwort leaves having several medicinal properties [24]. During cupping procedure practitioner initially warm a sharp needle with Moxa. To prevent skin burns, a thin aluminum layer is used as a barrier before applying the hot Moxa. Another type of cupping is herbal cupping in which herbal solution is used in cup that is soaked though the skin within 5-10 minutes [25]. In order to avoid skin burns, the cups are allowed to cool for one minute before being applied to the treated area of body.

\subsection{Magnetic cupping}

Magnetic cupping is performed using magnetic cups that contain magnets. This magnetic therapy is commonly used for treating joint diseases that affect large joints like knees and elbows [26]. It is assumed that electromagnetic stimulation improves the therapeutic efficacy of cupping. This therapy is thought to be much effective among all therapies.

\subsection{Laser cupping}

Laser cupping is basically a new cupping device that works in tandem with cupping therapy. As an added benefit to cupping, an acupuncture laser probe is inserted inside the cups to stimulate specific acupuncture points [27]. This method has the advantage of providing a "double effect" of cupping therapy and laser acupuncture. There have been many contraindications regarding this type of therapy therefore it has not gained much popularity.

\subsection{Aquatic cupping}

Aquatic cupping is actually combination of cupping therapy and aquatic therapy in which cupping is done underwater as this is assumed that muscles can be stretched more effectively underwater [28]. Before placing the cup over the skin, the therapist will fill a third of a cup with warm water and insert a burning cotton wool into the cup [29]. This therapy is frequently used for rehabilitation and musculoskeletal related issues.

\subsection{Electric stimulation cupping}

Transcutaneous electrical nerve stimulation (TENS) is combined with cupping in electric stimulation cupping. It is primarily used to stimulate specific points and in cases of muscular pain [30]. It also has a dual effect, similar to laser cupping therapy, in that both electric and cupping stimulation the treated area.

\section{COMPLICATIONS AND SIDE EFFECTS OF CUPPING THERAPY}

Direct application of cupping therapy at some specific sites of the body is contraindicated as the generated negative pressure during cupping procedure is reported to be harmful. These sites are veins, arteries, nerves, injured skin, body orifices, eyes, lymph nodes, varicose veins bone fractures, and especially the sites of deep vein thrombosis [31]. Most of the studies conducted primarily addressed efficacy of cupping but there have been so many studies also reported its complications. Generally, some of the cases where serious permanent marks are left on the body even on the sensitive areas that are non-preventable. Cupping causes erythema, edema, and ecchymosis which are the most commonly observed side effects, skin burns are also strongly associated with cupping therapy. They can occur as a result of the following factors viz. excessive alcohol consumption, prolonged cupping therapy exposure, sensitive skin specifically in the elder patients and the use of fire during cupping procedure [32]. It has been reported in a medical case report that long-term exposure to high vacuum pressure for more than 20 minutes during cupping therapy may result in 


\section{International Journal of Current Science Research and Review}

ISSN: 2581-8341

Volume 04 Issue 07 July 2021

DOI: 10.47191/ijcsrr/V4-i7-16, Impact Factor: 5.825

IJCSRR@ 2021

Www.ijcsrr.org

separation of the epidermal layer from the dermal base of the skin. This severe complication has been linked specifically to cupping therapy [31]. In another scientific case report, it has been found that cupping therapy for about 40 minutes over the lower back resulted in severe pain immediately after cup removal and patient later developed bullae and crusting over the targeted body area [33]. One greater risk of cupping therapy is also the Exposure to blood-borne infections which potentially occur if infection control measures are not followed strictly. Several blood and secondary infections case have been reported so far in cupping patients. For instance, a case of factitial panniculitis and herpes simplex virus infection have been reported after cupping therapy $[34,35]$. Changes in atmospheric pressure have been identified as a risk factor for skin injury in a patient who was flying. This resulted in numerous blisters and different shades of redness, as well as petechiae, dense marks and ecchymosis [36].

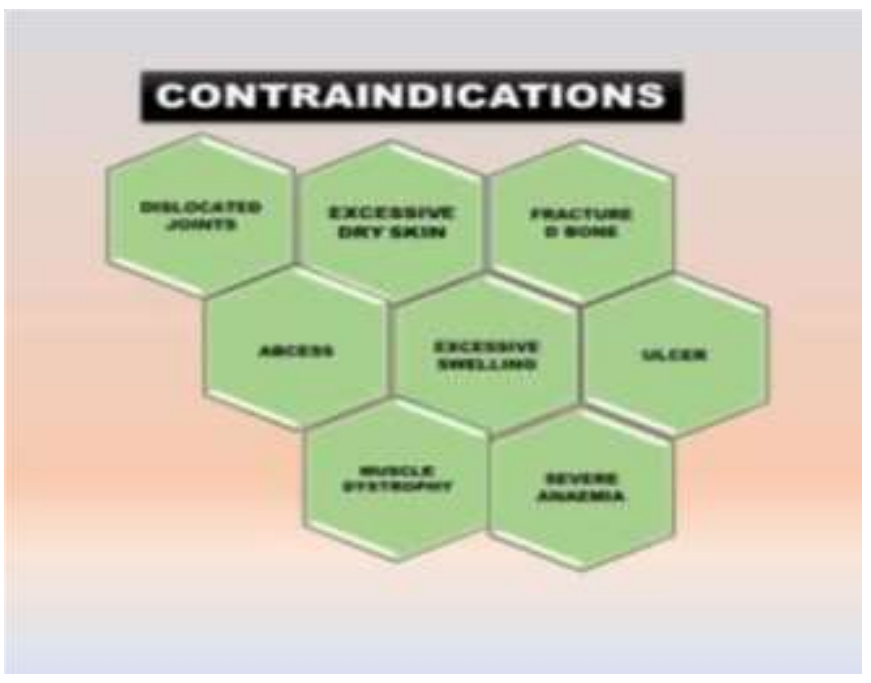

Figure 2: Contraindications of cupping therapy Cupping therapy contraindications are classified as either absolute or relative cupping is absolutely contraindicated in cancer patients and also those with any organ failure such as renal failure, hepatic failure, and heart failure until we have enough information about its safety this practice of cupping is not recommended. It is also completely contraindicated in patients who have a pacemaker and those who have hemophilia or other similar conditions [37, 38]. Cupping therapy adverse events (AEs) are frequently reported these includes headache, pruritus, muscle tension, dizziness, tiredness, nausea, anemia, bullae formation, small hematoma or severe pain at cupping site, abscess formation, skin infection, insomnia, hyperpigmentation, and vasovagal attack. Due to the serious side effects and severe consequences of cupping therapy application is limited and not much accepted in modern medical science.

\section{CONCLUSION}

Cupping therapy or Hijama is widely used as treatment for various ailment since ages. There are several theories which explains its mode of action, mechanism and also supports its effectiveness according to traditional Chinese Medicine, Unani Medicine or other traditional healing practices. This review delves deeply into the theories underlying cupping therapy's mechanisms and its implications. There is no single theory that can explain the mechanisms of action underlying cupping therapy, as well as its numerous effects. The available evidences do not support that cupping therapy has much effective. Its effectiveness is not well documentedfor nost of the medical conditions. According to evidences, cupping therapy may be effective in treating common chronic painful and inflammatory conditions for a short span of time. However, the majority of available studies have noteworthy limitations, such as insignificant sample size, different outcome assessment tools, treatment interval, and treatment regimens. Various serious side effect of cupping therapy is also reported from recent studies. There is need to address contemporary and traditional theories in light of modern innovation study. There is need of basic innovative research to verify and authenticate the discussed traditional cupping theories as well as to prose new theories. Large clinical trials with standard protocols and systematic reviews are need to conducted to support beneficial effects of cupping theory for future meta-analysis.

\section{ACKNOWLEDGEMENT}

The authors are thankful to Department of Zoology, Aligarh Muslim University for providing necessary facilities and aid

\section{REFERENCES}

1. Fleming S, Rabago DP, Mundt MP, Fleming MF. CAM therapies among primary care patients using opioid therapy for chronic pain. BMC Complementary and Alternative Medicine. 2007.

2. Kim, J. I., Lee, M. S., Lee, D. H., Boddy, K., \& Ernst, E. (2011). Cupping for treating pain: a systematic review. Evidencebased complementary and alternative medicine : eCAM, 2011, 467014. 


\section{International Journal of Current Science Research and Review}

ISSN: 2581-8341

Volume 04 Issue 07 July 2021

DOI: 10.47191/ijesrr/V4-i7-16, Impact Factor: 5.825

IJCSRR@ 2021

Www.ijcsrr.org

3. H. Christopoulou-Aletra, N. Papavramidou Cupping: an alternative surgical procedure used by hippocratic physicians J Altern Complement Med, 14 (8) (2008 Oct 1), pp. 899902.

4. A. lari, M. Nayab, M. Tausif, J. Lari, A. Alam Therapeutic potentials of hijama-bila-shart (dry cupping therapy): A review Int J Unani Integr Med, 1 (1) (2017).

5. M. Samadi, M. Kave, S. Mirghanizadeh Study of cupping and its role on the immune system J Relig Health, (2013).

6. Al-Bedah AMN, Elsubai IS, Qureshi NA, Aboushanab T, Ali G, El-Olemy A, et al. The medical perspective of cupping therapy: Effects and mechanisms of action. Journal of Traditional and Complementary Medicine. 2019;9(2):90-97.

7. Asma Al-Shidhani and Abdulaziz Al-Mahrezi The Role of Cupping Therapy in Pain Management 2020.

8. Hong SH, Wu F, Lu X, Cai Q, Guo Y. [Study on the mechanisms of cupping therapy]. Zhongguo Zhen Jiu. 2011.

9. Van Wijk G, Veldhuijzen DS. Perspective on diffuse noxious inhibitory controls as a model of endogenous pain modulation in clinical pain syndromes. J Pain. 2010;11(5):408-419.

10. Ann Lett RM. Reflex Zone Therapy for Health Professionals. first ed. 2000. pp. 2-20.

11. Shaban T. Cupping therapy Encyclopedia. 1st Ed. California: On-Demand Publishing; 2013.

12. Yoo SS., Tausk F. Cupping: east meets west. Int J Dermatol. 2004;43:664-665.

13. Staud R. Peripheral pain mechanisms in chronic widespread pain. Best Pract Res Clin Rheumatol. 2011;25(2):155-164.

14. Daniali F., VaezeMahdavi M.R., Ghazanfari T., Naseri M. Comparing of venous blood with Hijama blood according to biochemical and hematological factors and immunological responses. J Physiol Pharmacol. 2008;13:78-87.

15. Akbari Ahmad, Ali Seyed Mohammad, Zadeh Shariat, Ramezani Majid, Seyed, ShariatZadeh Mahdi. The effect of hijama (cupping) on oxidative stress indexes \& various blood factors in patients suffering from diabetes type ii. Switz. Res. Park J. 2013;102:9.

16. Khalil Ahmad Mohammad, Al-Qaoud Khaled Mahmoud, Shaqqour Hiba Mohammad. Investigation of selected immunocytogenetic effects of wet cupping in healthy men. Spatula DD. 2013;3:51-57. 2.

17. Gok Sumeyye, Liyagil Kazanci Fatma nur Haciev, Erdamar Husamettin, Gokgoz Nurcan. Is it possible to remove heavy metals from the body by wet cupping therapy (Al-hijamah)? Indian J. Tradit. Knowl. 2016;15:700-704.

18. Al-Bedah A, Aboushanab T, Alqaed M, Qureshi N, Suhaibani I, Ibrahim G et al. Classification of Cupping Therapy: A Tool for Modernization and Standardization. Journal of Complementary and Alternative Medical Research. 2016;1(1):1 10.DOI: $10.9734 /$ jocamr/2016/27222.

19. Tham LM, Lee HP, Lu C. Cupping: From a biomechanical perspective. Journal of Biomechanics. 2006;39(12):2183-2193. https://doi.org/10.1016/j.jbiomech.2005.06.027.

20. Cao H, Han M, Li X, Dong S, Shang Y, Wang Q, et al. Clinical research evidence of cupping therapy in China: A systematic literature review. BMC Complementary and Alternative Medicine. 2010;10(1):70. doi: 10.1186/1472-6882-1070.

21. Tham LM, Lee HP, Lu C. Cupping: From a biomechanical perspective. Journal of Biomechanics. 2006;39(12):2183-2193. https://doi.org/10.1016/j.jbiomech.2005.06.027.

22. Al-Shamma YM, Abdil Razzaq A. Al- Hijamah cupping therapy. Kufa Med J. 2009;12(1).

23. Teut M, Kaiser S, Ortiz M, Roll S, Binting S, Willich SN, et al. Pulsatile dry cupping in patients with osteoarthritis of the knee - a randomized controlled exploratory trial. BMC Complement Altern Med. 2012;12:184. Published 2012 Oct 12. doi:10.1186/1472-6882-12-184.

24. Anees S, Arafath $\mathrm{Y}$, Naaz A, Khan MQ. Hijamah (Cupping therapy) as a preventive medicine-a retro-prospective analytical study. International Journal of AYUSH. 2015;4(2):88-100.

25. Cao, H., Li, X., Han, M. and Liu, J., 2013. Acupoint Stimulation for Fibromyalgia: A Systematic Review of Randomized Controlled Trials. Evidence-Based Complementary and Alternative Medicine, 2013, pp.1-15.DOI: 10.1155/2013/362831.

26. Chirali, Ilkay Z. Traditional Chinese medicine cupping therapy. Elsevier Health Sciences. 2014;11,14,127,129.

27. Lin ML, Wu HC, Hsieh YH, Su CT, Shih YS, Lin CW, et al. Evaluation of the effect of laser acupuncture and cupping with ryodoraku and visual analog scale on low back pain. Evidence-Based Complementary and Alternative Medicine; 2012. 


\section{International Journal of Current Science Research and Review}

ISSN: 2581-8341

Volume 04 Issue 07 July 2021

DOI: 10.47191/ijesrr/V4-i7-16, Impact Factor: 5.825

IJCSRR@ 2021

www.ijcsrr.org

28. International Cupping Therapy Association (ICTA). Baguanfa treatments [Internet]. 2005. Available from: www.cuppingtherapy.org/pages/ applications.html.

29. Al-Rubaye KQ. The clinical and histological skin changes after the cupping therapy (Al- Hijamah). J Turk Acad Dermatol. 2012;6(1):1261a. DOI:10.6003/JTAD.1261A1.

30. Chirali, Ilkay Z. Traditional Chinese medicine cupping therapy. Elsevier Health Sciences. 2014;11,14,127,129.

31. Aboushanab T, AlSanad S. Cupping Therapy: An Overview from a Modern Medicine Perspective. Journal of Acupuncture and Meridian Studies. 2018;11(3):83-87. DOI: 10.1016/j.jams.2018.02.001.

32. Rozenfeld E, Kalichman L. New is the well-forgotten old: The use of dry cupping in musculoskeletal medicine. Journal of Bodywork and Movement Therapies. 2016;20(1):173-178. DOI:10.1016/j.jbmt.2015.11.009.

33. Tuncez F, Bagci Y, Kurtipek GS, Erkek E. Suction bullae as a complication of prolonged cupping. Clin Exp Dermatol. 2006;31(2):300-301. doi:10.1111/j.1365-2230.2005.02005.x.

34. Lee JS, Ahn SK, Lee SH. Factitial panniculitis induced by cupping and acupuncture. Cutis. 1995;55(4):217-218.

35. Jung YJ, Kim JH, Lee HJ, Bak H, Hong SP, Jeon SY, et al. A herpes simplex virus infection secondary to acupuncture and cupping. Ann Dermatol. 2011;23(1):67-69. doi:10.5021/ad.2011.23.1.67.

36. Lin CW, Wang JT, Choy CS, Tung HH. Iatrogenic bullae following cupping therapy. J Altern Complement Med. 2009;15(11):1243-1245. doi:10.1089/acm.2009.0282.

37. Cupping therapy regulation rules for practitioners and facilities, National Center for Complementary and Alternative medicine- Ministry of Health, Saudi Arabia (2015), p. 14.

38. Traditional and complementary medicine practice guidelines: on bekam, Traditional and Complementary medicine division. Ministry of Health, Malaysia. Kuala Lumpur (2011).

Cite this Article: Mudassir Alam, Kashif Abbas (2021). The Role of Cupping Therapy (CT) In Pain Tackling, an Insight into Mechanism Therapeutic Effects and its Relevance in Current Medical Scenario. International Journal of Current Science Research and Review, 4(7), $732-739$ 